University of Nebraska - Lincoln

DigitalCommons@University of Nebraska - Lincoln

USDA National Wildlife Research Center - Staff Publications
U.S. Department of Agriculture: Animal and Plant Health Inspection Service

2012

\title{
Summer and Migrational Movements of Satellite-Marked Doublecrested Cormorants from a Breeding Colony Managed by Egg-Oiling in Lake Ontario, USA
}

\author{
Brian S. Dorr \\ Mississippi State University, brian.s.dorr@aphis.usda.gov \\ Jimmy D. Taylor II \\ Mississippi State University, jimmy.d.taylor@usda.gov \\ Scott J. Werner \\ Mississippi State University, scott.j.werner@aphis.usda.gov \\ D. Tommy King \\ Mississippi State University, tommy.king@aphis.usda.gov \\ James F. Farquhar \\ New York State Department of Environmental Conservation
}

See next page for additional authors

Follow this and additional works at: https://digitalcommons.unl.edu/icwdm_usdanwrc

Part of the Life Sciences Commons

Dorr, Brian S.; Taylor, Jimmy D. II; Werner, Scott J.; King, D. Tommy; Farquhar, James F.; Mazzocchi, Irene M.; and McCullough, Russell D., "Summer and Migrational Movements of Satellite-Marked Doublecrested Cormorants from a Breeding Colony Managed by Egg-Oiling in Lake Ontario, USA" (2012). USDA National Wildlife Research Center - Staff Publications. 1501.

https://digitalcommons.unl.edu/icwdm_usdanwrc/1501

This Article is brought to you for free and open access by the U.S. Department of Agriculture: Animal and Plant Health Inspection Service at DigitalCommons@University of Nebraska - Lincoln. It has been accepted for inclusion in USDA National Wildlife Research Center - Staff Publications by an authorized administrator of DigitalCommons@University of Nebraska - Lincoln. 


\section{Authors}

Brian S. Dorr, Jimmy D. Taylor II, Scott J. Werner, D. Tommy King, James F. Farquhar, Irene M. Mazzocchi, and Russell D. McCullough 


\title{
Summer and Migrational Movements of Satellite-Marked Double- crested Cormorants from a Breeding Colony Managed by Egg-Oiling in Lake Ontario, USA
}

\author{
Brian S. Dorr ${ }^{1, *}$, Jimmy D. Taylor $\mathrm{II}^{1,3}$, Scott J. Werner ${ }^{1,4}$, D. Tommy King ${ }^{1}$, James F. Farquhar ${ }^{2}$, \\ Irene M. Mazzocchi ${ }^{2}$ and Russell D. Mccullough ${ }^{2}$ \\ ${ }^{1}$ U.S. Department of Agriculture, Wildlife Services, National Wildlife Research Center, P.O. Box 6099, \\ Mississippi State University, MS, 39762, USA
}

${ }^{2}$ New York State Department of Environmental Conservation, 317 Washington Street, Watertown, NY, 13601, USA

${ }^{3}$ Present Address: U.S. Department of Agriculture, Wildlife Services, National Wildlife Research Center, Oregon State University - 321 Richardson Hall, 3180 SW Jefferson Way, Corvallis, OR, 97331, USA

${ }^{4}$ Present Address: U.S. Department of Agriculture, Wildlife Services, National Wildlife Research Center, 4101 LaPorte Avenue, Ft. Collins, CO, 80521-2154, USA

*Corresponding author; E-mail: brian.s.dorr@aphis.usda.gov

\begin{abstract}
A two-year satellite telemetry study was initiated in May 2000 at a Double-crested Cormorant (Phalacrocorax auritus) breeding colony on Little Galloo Island (LGI) in eastern Lake Ontario, New York, USA, which is managed by egg-oiling. The objective was to describe cormorant ( $\mathrm{N}=26$ /year) movements, specifically during the period of reproductive management by egg-oiling and seasonally (breeding, migration and wintering). Egg-oiling at two-week intervals resulted in a hatch success on LGI of $5.7 \%$ for 2000 and 2001, combined. The majority (97\%) of core use areas of marked cormorants contained LGI throughout three egg-oiling treatments (six weeks), and $71 \%$ still contained LGI by the end of the final (fourth) treatment (eight weeks). Of cormorants that moved during or after control activities, three remained in the vicinity of active breeding colonies for over three months. Cormorants initiated fall migration over a 16-week period ranging from 12 July to 29 October, with a mean departure date of 6 September $(\mathrm{N}=24, \mathrm{SE}=8$ days $)$ over both years. Mean duration of fall migration was 34 days $(\mathrm{N}=19, \mathrm{SE}=7$ days, range $=108$ days $)$. Most $(75 \%)$ cormorants captured at LGI migrated east of the Appalachian Mountains, and their winter range extended from southeastern Louisiana, along the coast of the Gulf of Mexico, to the southern portion of the Atlantic coast. Although three (13\%) cormorants over both years relocated to other active colonies for long enough periods (over three months) to potentially raise young, this study indicates that control efforts did not result in complete abandonment of LGI. Egg-oiling was successful in reducing recruitment within breeding seasons, and within-breeding-season renesting attempts by cormorants in this study were limited and likely unsuccessful. Further evaluation and refinement of egg-oiling as a management tool will require multiyear monitoring of the LGI cormorant breeding colony. Received 9 September 2007, accepted 11 October 2009.
\end{abstract}

Key words._-cormorant, home-range, Phalacrocorax auritus, population control, recreational fisheries, reproductive control, satellite telemetry.

Waterbirds 35(Special Publication 1): 114-123, 2012

The Double-crested Cormorant (Phalacrocorax auritus; hereafter cormorant) is the most numerous and widely distributed of the six North American cormorant species (Hatch and Weseloh 1999). Human persecution in the $19^{\text {th }}$ and early $20^{\text {th }}$ centuries, coupled with environmental contamination through the early 1970s (Hatch 1995; Hatch and Weseloh 1999), severely reduced population levels of cormorants throughout North America (Ludwig 1984; Hatch and Weseloh 1999; Wires et al. 2001). Response to increased human environmental awareness (i.e. reduction of environmental contaminants and regulatory protection of the species) over the past three decades facilitated a population resurgence of cormorants in North America, particularly in the interior (Glahn et al. 2000). In addition, changes in fish communities on the breeding (Hatch and Weseloh 1999) and wintering grounds (Glahn et al. 2000) likely contributed to an increase in cormorant numbers with numbers in some areas doubling in under five years (Hatch and Weseloh 1999).

While the overall rate of growth in the North American cormorant populations slowed during the early 1990s (Tyson et al. 1999), population increases continued in some areas. In the Great Lakes, nesting pairs 
of cormorants increased from a low of about 200 pairs in the early 1970s (Ludwig 1984) to 115,000 pairs in the 2000 breeding season, with cormorants being most abundant in Lake Huron and Lake Ontario (OMNR 2006). Concomitant with increases in cormorants in Lake Ontario, declines of select fish species preyed on by cormorants and important to recreational anglers have been observed, causing concern among anglers and fisheries managers in the region (Schneider et al. 1999). Following studies conducted by the New York State Department of Environmental Conservation (NYSDEC), Schneider et al. (1999) concluded that cormorants impacted recreational fisheries, particularly Smallmouth Bass (Micropterus dolimieu), in the eastern basin of Lake Ontario (ELO). Due to declines in fish populations (Schneider et al. 1999) and threats to native biodiversity, the NYSDEC introduced control activities at cormorant breeding colonies in the ELO in 1994 and Little Galloo Island (LGI; Fig. 1) specifically in 1999 (Schneider et al. 1999; Farquhar et al. 2002).

As part of the NYSDEC efforts to assess management actions, we began monitoring movements of cormorants following

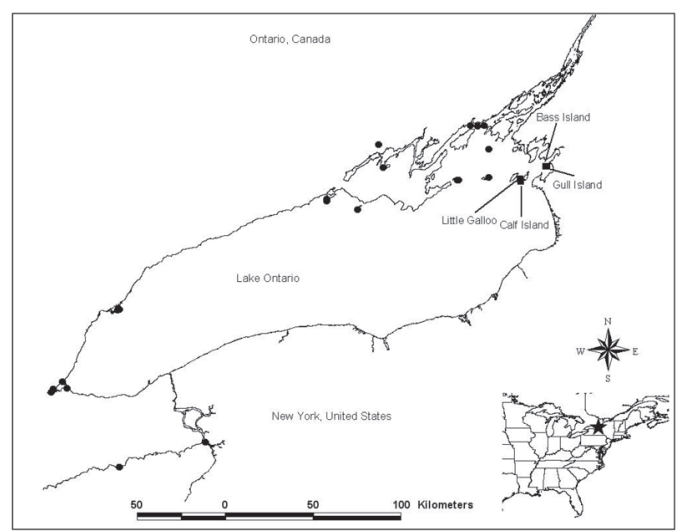

Figure 1. Study area of 52 Double-crested Cormorants captured, fitted with satellite transmitters and released on Little Galloo Island (filled star, inset), Lake Ontario (26 marked on 2-3 May 2000; 26 marked on 7 May 2001). Movements were monitored between 2 May 2000 and 19 April 2002. Gull, Calf, Bass, and Little Galloo Islands are sites where the New York Department of Environmental Conservation conducted Double-crested Cormorant control activities. Filled circles are other active colonies in the United States and Canada. colony control activities at LGI. The objectives were to evaluate effects of repeated egg-oiling treatments on within-breedingseason movement of cormorants captured and released on LGI and to provide baseline information on seasonal and migratory movements of managed cormorants. Specific to egg-oiling, this study evaluated whether egg-oiling would achieve the desired outcome of reproductive suppression without nest abandonment over the treatment period. It also evaluated whether cormorants that abandoned LGI would have adequate time to find alternate nest sites, re-nest and fledge young before southward migration.

\section{Methods}

\section{Study Area}

LGI is located in eastern Lake Ontario (Fig. 1). The island is a tilted limestone shelf, approximately 16.2 ha in size, with a thin layer of soil. Most of the island is covered by herbaceous vegetation, with a few trees present, primarily around the perimeter.

\section{Egg-oiling and Colony Observations}

A U.S. Fish and Wildlife Service depredation permit was obtained by NYSDEC to permit oiling of eggs on LGI (Farquhar et al. 2002). All accessible cormorant nests on LGI were treated with pure food-grade vegetable oil at two-week intervals on 16 and 30 May and 14 and 28 June 2000, and 15 and 29 May and 12 and 26 June 2001 (Farquhar et al. 2002). Oil was applied from a backpack sprayer at a rate of approximately six ml/egg (Farquhar et al. 2002). Concomitant with treatment applications, we recorded total number of nests with and without eggs, total nests oiled, total eggs oiled, number of inaccessible nests and number of chicks hatched. Additional management activities included the collection of regurgitated pellets for food habit studies. These collections were coordinated during egg-oiling to minimize disturbance not associated with egg-oiling.

Capture and Transmitter Attachment

Cormorants were captured on LGI $(\mathrm{N}=26$ on 2-3 May 2000; N = 26 on 7 May 2001; USGS Federal Bird Banding Permit 20873) using modified padded leghold traps (King et al. 2000) on or next to occupied nests. Cormorants were fitted with a satellite transmitter using a backpack harness (Dunstan 1972; King et al. 2000) and released at the capture site. In May 2000, a 45-g PTT-100 transmitter manufactured by Microwave Telemetry, Inc. (Columbia, Maryland) was used. The transmitters were programmed to transmit approximately eight hours 
(i.e. at most, eight locations/day) every 48 hours from May to September 2000, and eight hours every ten days from October 2000 to September 2001. In May 2001, we deployed an improved design transmitter that allowed a 15-g weight reduction per transmitter (new weight $=$ $30 \mathrm{~g}$ ) and similar performance. In 2001, transmitters were programmed to transmit approximately six hours (at most, six locations/day) every 48 hours from May to September 2001 and six hours every ten days from October 2001 to September 2002. Service Argos (ARGOS) Inc. (Landover, Maryland) provided location data. Location error was reported by Service Argos as one of six location classes (LCs): LC3 $=<150 \mathrm{~m}$, LC2 $=150-350 \mathrm{~m}$, LC1 $=350-1000 \mathrm{~m}, \mathrm{LC} 0>1000 \mathrm{~m}, \mathrm{LCA}$ and LCB $=$ no estimate of location accuracy.

\section{Data Analyses}

The location classes assigned by ARGOS predict relative accuracy of the location estimates based on expected error distributions for each location class (Steenhof et al. 2005). In practice, field measurements may be less accurate than reported error classes (Britten et al. 1999). Although ARGOS does not provide accuracy estimates for some location classes, this does not mean those locations are inaccurate (Vincent $e t$ al. 2002). Due to these factors, PC-SAS ARGOS Filter Version 2.4 (PC-ARGOS) was used to remove erroneous data points (Douglas 2000). Criteria that retained all location classes LC1-3 were selected and all remaining locations were filtered based on algorithms and userspecified criteria (Douglas 2000). The user-specified information for the filters included flight speed $(40 \mathrm{~km} /$ hour) and daily movement of $60 \mathrm{~km} /$ day (Custer and Bunck 1992). The subset of locations generated by PCARGOS was analyzed and plotted using a geographic information system (GIS; ArcView, ESRI Inc., Redlands, California). Data were not filtered for autocorrelation because all data were evaluated with the individual as the experimental unit (Otis and White 1999), and restrictive sub-sampling to eliminate autocorrelation reduces biological relevance in home range estimation (De Solla et al. 1999).

The Animal Movement Extension (AME) in ArcView was used to calculate $50 \%$ (core use area) and 95\% kernel home-range polygons for each cormorant at two-week intervals throughout the breeding season (Hooge and Eichenlaub 1997). The Xtools extension (DeLaune 2000) in ArcView was used to calculate the geometric center of each $50 \%$ core use area ('core use center') for the 14-day (2000) and eight-day (2001) period prior to egg-oiling ('pre-treatment') and for each of four two-week periods following egg-oiling ("treatment') to evaluate home range stability (Diffenbach $e t$ al. 2006). The effects of egg-oiling on resulting shifts in distance $(\mathrm{km})$ of cormorant core use centers from LGI were evaluated using a two-way analysis of variance (ANOVA; SAS Institute, Inc. 1996). Fixed-effects tested were treatment period, year, and the year $\times$ treatment interaction. Tukey's multiple range test was used to determine differences between group means $(\alpha=0.05)$. Core use area polygons were overlaid with known col- ony sites to qualify intercolony movement during treatment periods. Cormorants whose core area no longer included LGI were considered to have abandoned LGI for breeding purposes.

Hatch and Weseloh (1999) indicated that cormorants need a minimum of three months to successfully nest and raise young to independence from parental care. All breeding season locations were plotted and each individual's breeding season core use area was generated using AME (Hooge and Eichenlaub 1997). Intercolony movements were qualitatively evaluated by noting whether cormorant core use areas moved away from LGI during egg-oiling or they showed over three months near an active breeding colony following departure. Based on the aforementioned criteria from Hatch and Weseloh (1999), abandonment of LGI following treatment periods was also considered. Thus, we considered it possible for a cormorant to remain in the vicinity of LGI through the treatment periods, re-nest at a subsequent site, fledge young and migrate south in late October or November.

Departure date for fall migration was defined as the median date between the last location north of Lakes Ontario, Erie, Oneida and Onondaga and the first location date in which birds were detected and remained south of these lakes (Martell et al. 2001). Wintering locations were regarded as those observed between the median date between the last location of fall migration and the median date between the first spring migration location dates. All wintering season locations were plotted and each individual's wintering home-range and core use area were generated using AME (Hooge and Eichenlaub 1997).

\section{RESULTS}

\section{Egg-oiling and Colony Observations}

An estimated 5,119 and 5,440 breeding pairs of cormorants nested on LGI in 2000 and 2001, respectively, based on the maximum number of nests observed annually (Farquhar et al. 2002). Egg-oiling of all ground nests reduced hatching rate of oiled eggs to $<1 \%$ of total eggs counted, although approximately 200 and 400 young were fledged from untreated tree nests on LGI in 2000 and 2001, respectively. Thus, hatch success (number of nests with young out of total number of nests) on LGI was reduced to $5.7 \%$ for breeding seasons 2000 and 2001 combined (Farquhar et al. 2002). Annual counts indicate decreasing cormorant nests on LGI and increasing nests on ELO colonies both before and after egg-oiling was initiated on LGI in 1999 (Fig. 2). 


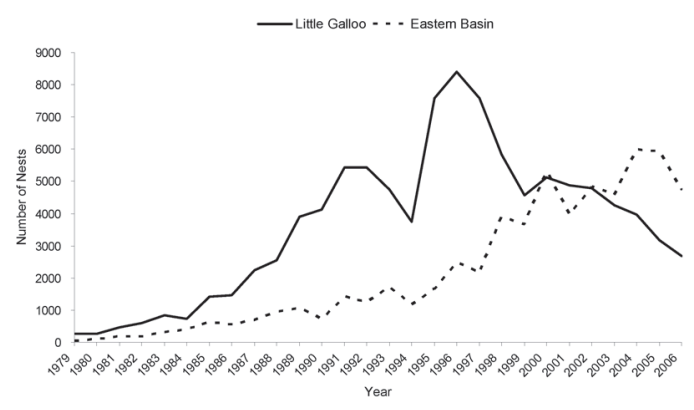

Figure 2. Number of cormorant nesting pairs counted on breeding colonies in the eastern basin of Lake Ontario, 1979 to 2006. Dotted line indicates counts for colonies in the eastern basin other than Little Galloo Island (LGI), New York, USA. Solid line shows counts for LGI. Data provided by D. V. Weseloh, Canadian Wildlife Service, and the New York State Department of Environmental Conservation. Egg-oiling management on LGI was initiated in 1999.

\section{Satellite Telemetry}

In total, 12,535 locations were collected for 52 cormorants captured and released on LGI. The PC-ARGOS program filtered out $958(7.6 \%)$ locations, resulting in 11,577 locations used for analyses. For the 26 individuals marked on 2 May 2000, 5,150 locations were recorded from 2 May 2000 to 13 October 2001. Individuals marked on 7 May 2001 yielded 6,427 locations from 7 May 2001 to 19 April 2002. Mean $( \pm$ SD) number of days on which transmitter signals were received was $149 \pm 172(\mathrm{~N}=26$; range $=6$-529) for birds marked in 2000 and $179 \pm 80(\mathrm{~N}=26$; range $=23-347)$ in 2001. Mean $( \pm \mathrm{SD})$ number of locations was $421 \pm 196(\mathrm{~N}=26$, range $=15$-633) for birds marked in 2000 and 276 $\pm 83(\mathrm{~N}=26$, range $=57-406)$ in 2001. Mean $( \pm \mathrm{SD})$ number of locations, per transmission period per bird was $3.6 \pm 1.9(\mathrm{~N}=1,433)$ for birds marked in 2000 and $2.4 \pm .03(\mathrm{~N}=$ 2,698 ) in 2001.

Twenty transmitters stopped signaling before the end of the fourth treatment period, and one cormorant was removed from distance analyses because it moved $>550 \mathrm{~km}$ away from LGI during treatment periods and was considered an outlier. Thus, the effects of egg-oiling were tested on changes in home-range size and shifts in core use areas for the remaining 31 cormorants. Seven additional transmitters stopped signaling before fall migration; thus, 24 cormorants were used to assess intercolony movement and the potential for individuals to fledge young from alternate nest sites. Nineteen transmitters continued to signal through fall migration, two of which persisted through to the subsequent spring, and one transmitter was still functional when the bird returned to the breeding grounds.

\section{Movements during Egg-Oiling}

Mean distance from core use centers to LGI differed with respect to treatment pe$\operatorname{riod}\left(F_{4,145}=4.4, \mathrm{P}=0.02\right)$. Tukey's multiple range test indicated that distance between core use centers and LGI was greatest ( $P$ $<0.05)$ in treatment period four for both years combined (Table 1). Area $\left(\mathrm{km}^{2}\right)$ of $50 \%$ core use was affected by an interaction of year and treatment $\left(F_{4,145}=3.3, \mathrm{P}=0.01\right)$; thus individual means are reported in Table 2. Area $\left(\mathrm{km}^{2}\right)$ of the $95 \%$ kernel home range also was affected by the year $\times$ treatment interaction $\left(F_{4,145}=3.2, \mathrm{P}=0.01\right.$; Table 2$)$. Over the entire treatment period, mean \pm SE $50 \%$ core use areas were $6 \pm 6 \mathrm{~km}^{2}$ in 2000 and $10 \pm 2 \mathrm{~km}^{2}$ in 2001. Mean \pm SE $95 \%$ kernel home-range areas were $42 \pm 44 \mathrm{~km}^{2}$ in 2000 and $75 \pm 13 \mathrm{~km}^{2}$ in 2001 .

Core use areas were plotted and qualitatively evaluated by treatment period for 31 cormorants. Core use areas of twelve cormorants $(39 \%)$ did not contain LGI during more than one treatment period; however, three of these twelve cormorants returned to the vicinity of LGI before treatments ended (Table 3). Thus, $71 \%$ (22) of marked cormorants showed fidelity to their nesting colony on LGI during the entire ten-week monitoring period for both years. Eight of the nine birds that left and did not return during control activities did not leave until the final (fourth) treatment period (Table 3). Therefore, the core use areas of $30(97 \%)$ of the 31 birds contained LGI prior to the final treatment period (Table 3). The percentage of cormorants whose core use areas did not contain LGI for each two-week treatment period is presented in Table 3 . 
Table 1. Mean (SE) distance of $50 \%$ kernel home-range centers of Double-crested Cormorants from Little Galloo Island, Lake Ontario, for pre-treatment and four treatment periods (two weeks each), 2 May to 11 July $2000-2001$. Sample size in all treatment periods was 31 birds.

\begin{tabular}{lccc}
\hline \hline Treatment period & Treatment date $2000(2001)$ & Breeding phenology & Mean $(\mathrm{SE}) \mathrm{km}$ \\
\hline Pre-treatment & $2(7)$ May & Laying & $6(1)$ \\
1 & $15(16)$ May & Laying/incubation & $6(1)$ \\
2 & $29(30)$ May & Incubation/nestling & $8(2)$ \\
3 & $12(14)$ June & Nestling & $9(3)$ \\
4 & $28(26)$ June & Nestling/fledgling & $23(6)^{\mathrm{a}}$ \\
\hline
\end{tabular}

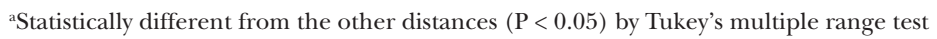

\section{Seasonal and Migratory Movements}

Twenty-four cormorants transmitted locations up to fall migration. For these birds, mean \pm SE breeding season $50 \%$ core use area was $820 \pm 368.5 \mathrm{~km}^{2}$ in 2000 and 1,207 $\pm 503 \mathrm{~km}^{2}$ in 2001 . Mean \pm SE breeding season $95 \%$ kernel home-range areas in 2000 and 2001 were $4,647 \pm 1,933 \mathrm{~km}^{2}$ and 8,120 $\pm 2,807 \mathrm{~km}^{2}$, respectively. Core areas of six $(25 \%)$ of these birds contained LGI until initiation of fall migration. Of the remaining 18 birds, seven (29\%) shifted core areas away from LGI during egg-oiling treatments, and eleven (46\%) shifted after all treatments. Six birds began fall migration by the end of July (i.e. within three weeks of the completion of the fourth treatment period). Of the remaining twelve birds, four moved northeast up the St. Lawrence River; two remained in Lake Ontario but not on LGI; three moved south to Lakes Oneida and Onondaga; one moved southwest to Pymatuning Reservoir in western Pennsylvania; and two moved southwest to Lake Erie. Of all cormorants that moved during or after control activities, three $(13 \%)$ remained in the vicinity of single active breeding colonies for over three months. Two birds moved dur- ing egg-oiling treatments: Bird 4 on the St. Lawrence River near Montreal, where it remained until 29 October (Fig. 3) and Bird 28 on Middle Island in western Lake Erie, where it remained until 30 September (Fig. 3). On Day 16 after the final egg-oiling treatment, Bird 21 moved to the St. Lawrence River near Montreal, where it remained until 22 October (Fig. 3).

Cormorants initiated southerly migration over a 16-week period ranging from 12 July to 29 October. Mean departure date for fall migration was 6 September $(\mathrm{N}=24$, SE $=8$ days $)$. Mean arrival date on wintering grounds was 9 October $(\mathrm{N}=19, \mathrm{SE}=6$ days $)$. Mean duration of fall migration was 34 days $(\mathrm{N}=19, \mathrm{SE}=7$ days, range $=108$ days $)$. Of cormorants marked on LGI, 18 (75\%) traveled east of the Appalachian Mountains, primarily along the Atlantic and Gulf coasts (Fig. 4). The remaining 25\% traveled west of the Appalachian Mountains. Locations were received from six birds through March of the subsequent year in which they were marked and were used for winter home-range estimation. For these birds, mean \pm SE wintering season $50 \%$ core use area and $95 \%$ home range was $566 \pm 290$ $\mathrm{km}^{2}$ and 4,609 $\pm 2,002 \mathrm{~km}^{2}$, respectively. De-

Table 2. Mean (SE) area $\left(\mathrm{km}^{2}\right)$ of $50 \%$ and $95 \%$ kernel home ranges (HR) for cormorants captured in $2000(\mathrm{~N}=$ 8) and $2001(\mathrm{~N}=23)$ at Little Galloo Island, Lake Ontario, for pre-treatment and treatment periods, 2 May to 11 July 2000-2001.

\begin{tabular}{lcccccc}
\hline \hline & & \multicolumn{5}{c}{ Treatment period and date $2000(2001)$} \\
\cline { 3 - 6 } Year & $\begin{array}{c}\text { Kernel HR } \\
\text { size (\%) }\end{array}$ & $\begin{array}{c}\text { Pre-treatment } \\
2(7) \text { May }\end{array}$ & $15(16)$ May & $29(30)$ May & $12(14)$ June & $28(26)$ June \\
\hline 2000 & 50 & $3(1)$ & $2(0)$ & $2(1)$ & $3(1)$ & $18(12)$ \\
2001 & 50 & $9(2)$ & $13(3)$ & $10(2)$ & $12(2)$ & $7(1)$ \\
2000 & 95 & $23(4)$ & $20(3)$ & $19(4)$ & $20(5)$ & $130(96)$ \\
2001 & 95 & $68(16)$ & $91(16)$ & $75(12)$ & $85(15)$ & $57(7)$ \\
\hline
\end{tabular}


Table 3. Number of known colony sites (other than Little Galloo Island, LGI, Lake Ontario) within $50 \%$ kernel home-range polygons (core areas) for 31 cormorants captured and marked on LGI in May 2000 and 2001. The total row contains the number (and percent) of cormorants whose core use areas did not contain LGI by treatment period.

\begin{tabular}{|c|c|c|c|c|c|}
\hline \multirow{2}{*}{$\begin{array}{l}\text { Bird } \\
\text { ID no. }\end{array}$} & \multicolumn{5}{|c|}{$\begin{array}{l}\text { Known colony sites in core area during } \\
\text { treatment }{ }^{\mathrm{a}}\end{array}$} \\
\hline & Pre-treatment & 1 & 2 & 3 & 4 \\
\hline 01 & $1^{\mathrm{b}}$ & 0 & 1 & 0 & 0 \\
\hline 04 & 1 & $1^{\mathrm{b}}$ & 0 & 0 & 2 \\
\hline 07 & 1 & 1 & 0 & 0 & 1 \\
\hline 08 & 0 & 0 & 0 & 0 & 0 \\
\hline 09 & 0 & 0 & 0 & 0 & 0 \\
\hline 15 & 0 & 0 & 0 & 0 & $1^{\mathrm{b}}$ \\
\hline 16 & 0 & 0 & 0 & 0 & 0 \\
\hline 21 & 0 & 0 & 0 & 1 & 0 \\
\hline 27 & 1 & 2 & 0 & 0 & 2 \\
\hline 29 & 0 & 1 & 4 & 2 & $1^{\mathrm{b}}$ \\
\hline 30 & 0 & 0 & 0 & 1 & 1 \\
\hline 31 & 0 & 2 & 0 & 0 & 0 \\
\hline 32 & 0 & 0 & 1 & 1 & 0 \\
\hline 33 & 1 & 0 & 1 & 0 & 1 \\
\hline 35 & 0 & 6 & $1^{\mathrm{b}}$ & 1 & $1^{\mathrm{b}}$ \\
\hline 36 & 0 & 0 & 0 & 3 & 0 \\
\hline 37 & 3 & 2 & 2 & 0 & 0 \\
\hline 38 & 0 & 1 & 2 & 1 & 0 \\
\hline 39 & 0 & 1 & 1 & 1 & $1^{\mathrm{b}}$ \\
\hline 40 & 1 & 1 & $1^{\mathrm{b}}$ & 1 & $1^{\mathrm{b}}$ \\
\hline 42 & 1 & $1^{\mathrm{b}}$ & $1^{\mathrm{b}}$ & 1 & 0 \\
\hline 43 & 0 & 2 & 1 & 2 & 1 \\
\hline 44 & 0 & 1 & 1 & 2 & $2^{\mathrm{b}}$ \\
\hline 45 & 0 & 2 & 1 & 1 & 1 \\
\hline 46 & 0 & 0 & 2 & $3^{\mathrm{b}}$ & $1^{\mathrm{b}}$ \\
\hline 47 & 0 & 2 & 3 & 2 & $2^{\mathrm{b}}$ \\
\hline 48 & 0 & $\overline{1}$ & $1^{\mathrm{b}}$ & 3 & $1^{\mathrm{b}}$ \\
\hline 49 & 2 & 1 & 2 & 4 & 1 \\
\hline 50 & 0 & 0 & 0 & 1 & 0 \\
\hline 51 & 1 & 2 & 1 & 4 & 2 \\
\hline 52 & 1 & 0 & 0 & 0 & 0 \\
\hline Total $^{\mathrm{b}}$ & $1(3)$ & $2(6)$ & $4(13)$ & $1(3)$ & $9(32)$ \\
\hline
\end{tabular}

${ }^{a}$ Unless otherwise noted, core area contained LGI (i.e., $0=$ LGI; 1 = LGI plus an additional known colony). ${ }^{\mathrm{b}}$ Core area did not contain LGI

parture dates from the wintering grounds for the two surviving marked birds were 19 and 22 March 2001. Duration on the wintering grounds for these birds was 145 and 170 days.

\section{Discussion}

Egg-oiling effectively reduced groundnesting cormorant productivity on LGI by 94.3\%, exceeding NYSDEC's 90\% goal (Farquhar et al. 2002). Counts of nesting pairs

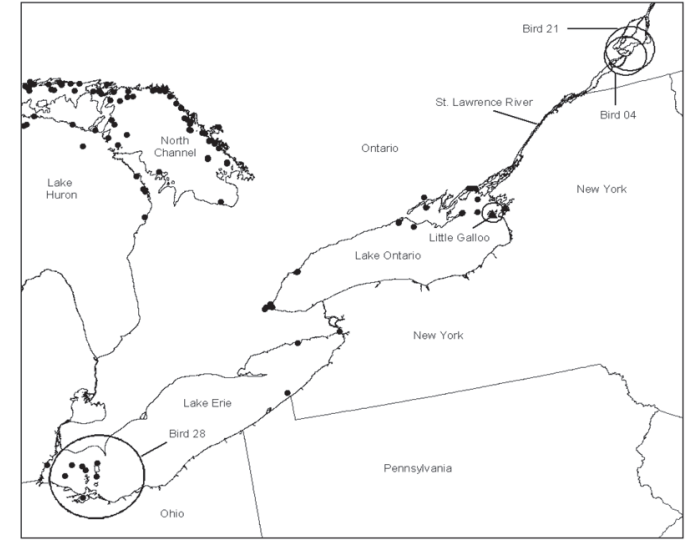

Figure 3. Breeding season (May to October) core use areas (50\% kernel home-range polygons) for three Double-crested Cormorants (Birds 4, 21 and 28) captured and released on Little Galloo Island, Lake Ontario, 2 May 2000 and 7 May 2001, which subsequently moved to other active colony sites for over three months. Filled circles are known colony sites; filled triangles are New York State Department of Environmental Conservation control sites.

on LGI suggest that egg-oiling has reduced growth in nesting pairs of cormorants on LGI relative to that seen elsewhere on Lake Ontario. However, success of these eggoiling efforts cannot be measured by the number of unhatched eggs alone, but must include minimization of re-nesting attempts through extended incubation or relocation (Gross 1951; Blackwell et al. 2000).

Abandonment of LGI, as measured through shifts in core use centers and area was minimal during the first eight weeks of the study (pre-treatment and treatments 1 to 3), suggesting negligible abandonment due to human activity (i.e. trapping and egg-oiling). Significant shifts in distance between $50 \%$ core use centers and LGI occurred only for the final (fourth) treatment period. While core areas of $71 \%$ of marked cormorants contained LGI at the end of the treatment periods, approximately half of those cormorants moved their core area away from LGI for more than one treatment period. Control efforts may not have resulted in complete abandonment of LGI by cormorants during the treatment period, but egg-oiling likely influenced temporary relocation to other colony sites within the breeding season. 


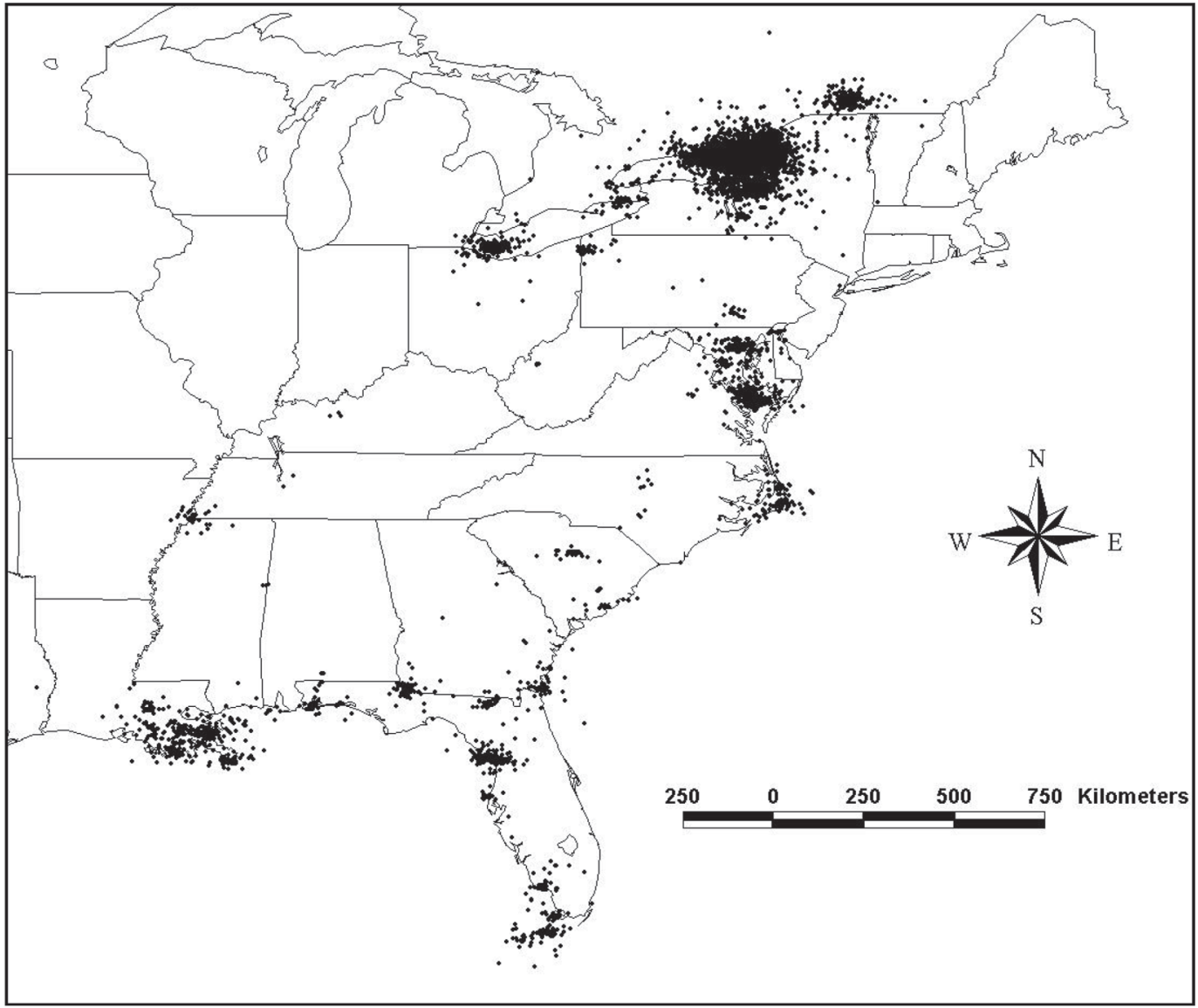

Figure 4. Locations of 52 Double-crested Cormorants captured, marked with satellite transmitters and released on Little Galloo Island, Lake Ontario, 2 May 2000 to 19 April 2002.

Several factors aside from human disturbance may have affected movement of cormorants away from LGI. Trends towards increasing distance from LGI, particularly by the fourth treatment period, coincide with the nestling and early fledging dates of initial nests on LGI (Hatch and Weseloh 1999). Movements away from LGI in later periods suggest that cormorants may have moved in response to unsuccessful nesting. However, other factors may have contributed to the observed movement pattern. For example, local depletion of food resources surrounding a breeding colony can also increase foraging distances of colonial birds (Ashmole 1963). Nevertheless, $97 \%$ of core use areas of marked cormorants contained LGI up to the end of the third treatment period. The NYSDEC control efforts on nearby active colony sites may have prevented LGI cormorants from nesting at those sites and thereby abandoning LGI. The proximity and availability of alternative nesting locations may affect abandonment of nesting areas due to control efforts.

A central question regarding termination of nesting attempts at a controlled site is whether nesting was resumed at other active colony sites. The success of the egg-oiling efforts could be negated if cormorants successfully re-nest at other locations nearby. Our data suggest that cormorant home ranges shifted away from LGI, particularly in later stages of control activities, yet most cormorants did not leave the ELO during this time period. Although there are many active colony sites in the ELO, only three cormorants remained over three months at loca- 
tions other than LGI. The spatial locations of these birds were widely dispersed suggesting that movements away from LGI were not directed toward the nearest untreated colony site. Although it is possible that these birds successfully raised young, the fact that two of these birds moved to an active colony in mid-July would likely have reduced chick survival. While some cormorants shifted their core use areas to other colonies, few if any remained at any active colony site long enough to successfully raise young to independence from parental care.

Knowledge of seasonal movement data for cormorants is limited. While core use centers shifted away from LGI, cormorant home ranges did not apparently increase with breeding phenology (laying to fledging). Increasing trends in home-range size associated with breeding phenology have been demonstrated in other bird species (Novoa et al. 2006; Rutz 2006) and is linked to energetic and foraging requirements of chick rearing (Hodum et al. 1998). An increasing trend was not observed with cormorants on LGI whose reproductive success was eliminated through egg-oiling and may reflect reduced energetic demand and foraging due to the absence of young. Although a predictable pattern in breeding season home-range extent was not apparent within years, home-range size showed significant inter-annual variation. Larger breeding season home ranges in 2001 may reflect both variability and patchiness in food resources (Nudds and Ankney 1982).

Migration of managed cormorants from LGI showed broad temporal and spatial variation. Departure dates of cormorants from their breeding grounds varied over a 16 -week period. The mean departure date (6 September) in this study corresponds with the range of peak departure dates for cormorants reported by Hatch and Weseloh (1999). Because activity data for non-managed cormorants breeding on LGI were not available, it is impossible to conclude that nest failure due to egg-oiling caused earlier migration. Further study of management effects on fall migration and fish consumption among cormorants in the ELO is recommended.
Most $(75 \%)$ cormorants captured at LGI migrated east of the Appalachian Mountains along or near the Atlantic coast (Fig. 4). Their winter range extended from southeastern Louisiana, along the coast of the Gulf of Mexico, to the southern portion of the Atlantic coast. The remaining cormorants generally migrated along the Mississippi Alluvial Valley, to coastal Louisiana. Cormorants marked at LGI generally follow a different migratory route than birds marked farther west (Dolbeer 1991). However, mixing on the wintering grounds with birds breeding in more interior regions would occur commonly. Evidence of morphological differences in cormorants captured on lakes in eastern Alabama versus cormorants captured $>300 \mathrm{~km}$ west in Mississippi (Glahn et al. 1999) indicate that this difference in migratory route may reflect meta-populations with differing physical characteristics.

Between 1997 and 1999, a sharp decline occurred in the number of nesting pairs on LGI. The decline was unlikely due to disturbance caused by food habit studies, as these studies had been ongoing since 1992, when colony size actually increased. However, during July 1998, over 850 birds were shot illegally, which likely contributed to the steep decline. Since the initiation of egg-oiling (1999) the number of nesting pairs of cormorants on LGI has gradually declined. The gradual nature of the decline was expected due to recruitment to the breeding population of cormorants hatched prior to eggoiling, longevity of adults, and the fact that most cormorants do not reach sexual maturity until age three (Hatch and Weseloh 1999). Over the same time period, colonies other than LGI in the ELO have continued to show increasing numbers of nesting pairs (Fig. 2). Our data corroborate the expected rate of decline based on population modeling done by NYSDEC (Farquhar et al. 2002). The corroboration between observed and modeled decline suggests either that most remaining birds are returning to the LGI colony site or that immigration is balancing emigration.

Evaluation of inter-annual site fidelity to LGI was beyond the scope of this study. How- 
ever, inter-annual site fidelity has important implications with regard to egg-oiling as a reproductive control method. If birds shift breeding activity from LGI to other colony sites, a decline in numbers on LGI may not be attributable to the effectiveness of eggoiling. Recent research on Lake Champlain indicated that egg-oiling caused 3\% greater immigration to another colony site (Duerr et al. 2006). However, Duerr et al. (2006) indicated that immigration is influenced by factors such as gull predation of nests during oiling and foraging quality of surrounding habitat. Data on between-year effects of management are important, because for long-lived birds such as cormorants, reproductive control methods such as egg-oiling have little effect on numbers of adults for an extended time period in the absence of lethal control (Bedard et al. 1995; Dolbeer 1998).

The management efforts initiated by NYSDEC have been operationally successful, reducing hatching success by $>90 \%$ and by causing a sustained downward trend in the number of nesting pairs. Declining nesting pairs combined with data indicating that the majority of cormorants are not successfully utilizing other colony sites to raise young within breeding seasons indicates that given long-term commitment, local colony reproductive control can be an effective management strategy for reducing the abundance of cormorants. However, to fully evaluate the potential and effects of egg-oiling as a management tool requires multiyear monitoring of the number of nesting pairs on LGI, and the immigration and emigration of cormorants between LGI and other colonies within and among years.

ACKNOWLEDGMENTS

The study was funded through a cooperative research agreement between USDA's National Wildlife Research Center and the New York State Department of Environmental Conservation (Cooperative Service Agreement Number 00-7407-0399 [RA]). We appreciate the assistance of M. Carrara, R. Chipman, P. Fioranelli, J. Gansowski, B. Harrel, A. Schiavone and D. V. Weseloh with planning and fieldwork. D. Douglas assisted with spatial data management and analyses. We thank S. Barras, J. C. Jones, M. Tobin and D. V. Weseloh for comments on the manuscript. The research was conducted under the following permits: US Department of Agriculture, Wildlife Services, National Wildlife Research Center's Institutional Animal Care and Use Committee Protocol QA-742 and US Department of Interior, US Geological Survey, Federal Bird Banding Permit 20873.

\section{Literature Cited}

Ashmole, N. P. 1963. The regulation of numbers of tropical oceanic birds. Ibis 103: 458-473.

Bedard, J., A. Nadeau and M. Lepage. 1995. Doublecrested Cormorant culling in the St. Lawrence River Estuary. Colonial Waterbirds 18 (Special Publication 1): 78-85.

Blackwell, B. F., M. A. Stapanian and D. V. C. Weseloh. 2000. Dynamics of the Double-crested Cormorant population on Lake Ontario. Wildlife Society Bulletin 30: 345-353.

Britten, M. W., P. L. Kennedy and S. Ambrose. 1999. Performance and accuracy evaluation of small satellite transmitters. Journal of Wildlife Management 63: 1349-1358.

Custer, T. W. and C. Bunck. 1992. Feeding flights of breeding Double-crested Cormorants at two Wisconsin colonies. Journal of Field Ornithology 63: 203-211.

DeLaune, M. G. 2000. Guide to the ODF XTools ArcView Extension (Version 10/18/2000). Oregon Department of Forestry, Salem. http://www.diskworld.net/AVDOCS/xtguide.pdf, accessed 29 November 2011.

De Solla, S. R., R. Bonduriansky and R. J. Brooks. 1999. Eliminating autocorrelation reduces biological relevance of home range estimates. Journal of Animal Ecology 68: 221-234.

Diffenbach, D. R., L. A. Hansen, R. J. Warren and M. J. Conroy. 2006. Spatial organization of a reintroduced population of bobcats. Journal of Mammalogy 87: 394-401.

Dolbeer, R. A. 1991. Migration patterns of Double-crested Cormorants east of the Rocky Mountains. Journal of Field Ornithology 62: 83-93

Dolbeer, R. A. 1998. Population dynamics: the foundation of wildlife damage management for the $21^{\text {st }}$ century. Vertebrate Pest Conference 18: 2-11.

Douglas, D. C. 2000. PC-SAS Argos Filter V2.4 Software Documentation. United States Geological Survey, Alaska Biological Science Center, Anchorage, Alaska. http:// alaska.usgs.gov/science/biology/spatial/ manual.html, accessed 10 November 2009.

Duerr, A. E., T. M. Donovan and D. E. Capen. 2006. Management-induced reproductive failure and breeding dispersal in Double-crested Cormorants on Lake Champlain. Journal of Wildlife Management 71: 2565-2574.

Dunstan, T. C. 1972. A harness technique for radiotagging raptorial birds. Inland Bird Banding News 44: 4-8. 
Farquhar, J. F., R. D. McCullough and I. M. Mazzocchi. 2002. Cormorant management activities in Lake Ontario's eastern basin. New York Department of Environmental Conservation Special Report, March 2002. http:// http://www.dec.ny.gov/docs/wildlife_ pdf/corm02sec2.pdf accessed 29 November 2011.

Glahn, J. F., M. E. Tobin and J. B. Harrel. 1999. Possible effects of catfish exploitation on overwinter body condition of Double-crested Cormorants. Pages 107-113 in Symposium on Double-crested Cormorants: population status and management issues in the Midwest. Technical Bulletin No. 1879 (M. E. Tobin, Tech. Coord.). U.S. Department of Agriculture, Animal and Plant Health Inspection Service, Washington, D.C.

Glahn, J. F., M. E. Tobin and B. F. Blackwell (Eds.). 2000. A science-based initiative to manage Doublecrested Cormorant damage to southern aquaculture. Technical Bulletin 11-55-010. U.S. Department of Agriculture, Animal and Plant Health Inspection Service, Wildlife Services, National Wildlife Research Center, Fort Collins, Colorado.

Gross, A. 1951. The Herring Gull-cormorant control project. Proceedings of the International Ornithological Congress 10: 532-536.

Hatch, J. J. 1995. Changing populations of Doublecrested Cormorants. Colonial Waterbirds 18 (Special Publication 1): 8-24.

Hatch, J. J. and D. V. Weseloh. 1999. Double-crested Cormorant (Phalacrocorax auritus). In The Birds of North America, No. 441 (A. Poole and F. Gill, Eds.). The Birds of North America, Inc., Philadelphia, Pennsylvania.

Hodum, P. J., W. J. Sydeman, G. H. Visser and W. W. Weathers. 1998. Energy expenditure and food requirement of Cassin's Auklets provisioning nestlings. Condor 100: 546-550.

Hooge, P. N. and B. Eichenlaub. 1997. Animal movement extension to ArcView version 1.1. Alaska Biological Science Center, U.S. Geological Survey, Anchorage, Alaska. http://www.absc.usgs.gov/glba/ gistools/animal_mvmt.htm, accessed 10 November 2009.

King, D. T., M. E. Tobin and M. Bur. 2000. Capture and telemetry techniques for Double-crested Cormorants (Phalacrocorax auritus). Pages 54-57 in Proceedings of the 19th Vertebrate Pest Conference (T. P. Salmon and A. C. Crabb, Eds.). University of California, Davis, California.

Ludwig, J. P. 1984. Decline, resurgence and population dynamics of Michigan and Great Lakes Doublecrested Cormorants. Jack-Pine Warbler 62: 91-102.

Martell, M. S., C. J. Henny, P. E. Nye and M. J. Solensky. 2001. Fall migration routes, timing, and wintering sites of North American Ospreys as determined by satellite telemetry. Condor 103: 715-724.
Novoa, C., S. Dumas and J. Resseguier. 2006. Homerange size of Pyrenean Grey Partridges Perdix perdix hispaniensis during the breeding season. Wildlife Biology 12: 11-18.

Nudds, T. D. and C. D. Ankney. 1982. Ecological correlates of territory and home-range size in North American dabbling ducks. Wildfowl 33: 58-62.

OMNR (Ontario Ministry of Natural Resources). 2006. Review of the status and management of Doublecrested Cormorants in Ontario. Ontario Ministry of Natural Resources, Fish and Wildlife Branch, Wildlife Section. Peterborough, Ontario. http:// www.mnr.gov.on.ca/stdprodconsume/groups/1r/@ $\mathrm{mnr}$ @fw/documents/document/stel02_196676. pdf, accessed July 2010.

Otis, D. L. and G. C. White. 1999. Autocorrelation of location estimates and the analysis of radiotracking data. Journal of Wildlife Management 63: 1039-1044.

Rutz, C. 2006. Home-range size, habitat use, activity patterns and hunting behavior of urban-breeding Northern Goshawks Accipiter gentilis. Ardea 94: 185-202.

SAS Institute, Inc. 1996. SAS/STAT software: changes and enhancements through release 6.11. SAS Institute, Incorporated. Cary, North Carolina.

Schneider, C. P., A. Schiavone, Jr., T. H. Eckert, R. D. McCullough, B. F. Lantry, D. W. Einhouse, J. R. Chrisman, C. M. Adams, J. H. Johnson and R. M. Ross. 1999. Double-crested Cormorant predation on Smallmouth Bass and other fishes of the eastern basin of Lake Ontario: overview and summary. NYSDEC Special Report. http://www.dec.ny.gov/docs/ wildlife_pdf/sect1.pdf, accessed 10 November 2009.

Steenhof, K., M. R. Fuller, M. N. Kochert and K. K. Bates. 2005. Long-range movements and breeding dispersal of Prairie Falcons from southwest Idaho. Condor 107: 481-496.

Tyson, L. A., J. L. Belant, F. J. Cuthbert and D. V. Weseloh. 1999. Nesting populations of Double-crested Cormorants in the United States and Canada. Pages 17-26 in Symposium on Double-crested Cormorants: population status and management issues in the Midwest. Technical Bulletin No. 1879 (M. E. Tobin, Tech. Coord.). U.S. Department of Agriculture, Animal and Plant Health Inspection Service, Washington, D.C.

Vincent, C., B. J. McConnell, V. Ridoux and M. Fedak. 2002. Assessment of Argos location accuracy from satellite tags deployed on captive gray seals. Marine Mammal Science 18: 156-166.

Wires, L. R., F. J. Cuthbert, D. R. Trexel and A. R. Joshi. 2001. Status of the Double-crested Cormorant (Phalacrocorax auritus) in North America. Final Report to US Fish and Wildlife Service. University of Minnesota, St. Paul, Minnesota. http://library.fws. gov/Bird_Publications/cormorant_status01.pdf, accessed 10 November 2009. 